\title{
The Diversity Gap: when diversity matters for knowledge
}

\author{
Justin Sulik \\ Cognition, Values and Behavior \\ Ludwig Maximilian University of Munich
}

\author{
Bahador Bahrami \\ Department of Psychology \\ Ludwig Maximilian University of Munich, \\ Department of Psychology \\ Royal Holloway, University of London
}

\author{
Ophelia Deroy \\ Faculty of Philosophy \& Munich Center for Neurosciences \\ Ludwig Maximilian University of Munich, \\ Institute of Philosophy, School of Advanced Study, \\ University of London
}

\begin{abstract}
Can diversity make for better science? Although diversity has ethical and political value, arguments for its epistemic value require a bridge between normative and mechanistic considerations, demonstrating why and how diversity benefits collective intelligence. However, a major hurdle is that the benefits themselves are rather mixed: quantitative evidence from psychology and behavioral sciences sometimes shows a positive epistemic effect of diversity, but often shows a null effect, or even a negative effect. Here we argue that, in order to make progress with these why and how questions, we need first to rethink when one ought to expect a benefit of cognitive diversity. In doing so, we highlight that the benefits of cognitive diversity are not equally distributed about collective intelligence tasks, and are best seen for complex, multistage, creative problem solving, during problem posing and hypothesis generation. Throughout, we additionally outline a series of mechanisms relating diversity and problem complexity, and show how this perspective can inform meta-science questions.
\end{abstract}

Keywords: diversity, problem solving, complexity, creativity, interaction, perspective taking

Diversity is valuable for obvious reasons of justice and fairness. But is it similarly important for knowledge? Does it make for better science (Intemann, 2009, Medin, 2017)? Arguments from fairness do not immediately translate into arguments about epistemic outcomes (Intemann, 2009), so we will show why diversity is good for problem solving, and especially for the kind of complex problem solving involved in doing science.

This claim may sound unnecessary: are positive empirical results (e.g., AlShebli, Rahwan, \& Woon, 2018, Bosetti, Cattaneo, \& Verdolini, 2012, Campbell, Mehtani, Dozier, \& Rinehart, 2013; Nielsen et al., 2017) not sufficient to settle the matter? However, existing evidence and arguments do not settle the issue, as they are not shared across the multiple disciplines concerned with diversity, such as philosophy, psychology, cultural evolution, economics, or manage-

This research was funded by the NOMIS Foundation through the project "Diversity in Social Environments"

Preprint (10 May 2021). This paper has been accepted at Perspectives on Psychological Science. DOI for in-press manuscript will be added here when available. ment/organizational sciences. Normative approaches typically demonstrate clear benefits of diversity, whereas more applied approaches commonly report weak or null effects, or find that these benefits are often outweighed by various costs (Bell, Villado, Lukasik, Belau, \& Briggs, 2011; Horwitz \& Horwitz, 2007; Stahl, Maznevski, Voigt, \& Jonsen, 2010, Van Knippenberg \& Schippers, 2007, Williams \& O'Reilly, 1998).

Our goal is to address this Diversity Gap - the gap between the promise and reality of diversity, or between what we normatively think ought to be the case and what empirically is the case. Specifically, we tackle two core questions: how to explain the Diversity Gap, and how to close it.

The main concern here will be epistemic or cognitive diversity: the various ways in which people use and store information, including knowledge, beliefs, ability, expertise, goals, or values. This can theoretically be distinguished from diversity in surface or demographic factors such as age, ethnicity or gender (Hong \& Page, 2004: Roberson, Ryan, \& Ragins, 2017; Van Knippenberg, De Dreu, \& Homan 2004, Williams \& O'Reilly, 1998). However, it is unhelpful to insist on a clear distinction between these broad types of diversity (Van Dijk, Van Engen, \& Van Knippenberg, 2012, Van Knippenberg et al. 2004). Demographic and cognitive diversity often interact, as demographic differences can affect 
what information people have via different life experiences or cultural values (Barrett, 2020, Bohman, 2006, Gutiérrez \& Rogoff, 2003; Hanel et al., 2018; Ragins, Lyness, Williams, \& Winkel, 2014, Taras, Kirkman, \& Steel, 2010, Williams \& O'Reilly, 1998). Demographic differences can also affect how people share information, if they are biased to gain information from those more similar to themselves or to distrust information from those who are different (Mannix \& Neale, 2005, Van Knippenberg et al., 2004).

Thus, we suggest, articulating and distinguishing demographic and cognitive sources of diversity matters less than the informational vs. interactive domains in which the effects of those factors play out. 'Informational' refers to the contributions that individuals bring to collective endeavors: the relevant information that may help solve the problem. 'Interactive' refers to the ways in which the group makes use of those contributions while collaborating: the ways in which relevant information is shared, integrated, aggregated and implemented. Both demographic and cognitive factors can have an effect in both informational and interactional domains. For instance, in science, immigrant status can simultaneously evince informational benefits and interactional costs (Hofstra et al. 2020).

\section{The benefits of diversity}

Three main approaches make the case that diversity is epistemically beneficial. Philosophy provides a normative account: why diversity ought to be useful. Computational modeling provides a bridge between the normative and empirical: how the theoretical effects of having diverse individuals is likely to play out to yield group-level effects. Finally, empirical studies speak to the question of whether these effects are in fact realized.

Philosophical accounts of the benefits of diversity date back to Aristotle: if each individual contributes some practical wisdom, then the collective can yield better judgment by pooling these individual contributions (Waldron, 1995). Mill (1989) further argued that the optimal epistemic outcome for the group depends not only on the range of opinions on offer, but also on the deliberation provoked by this range, highlighting the need for both informational and interactional domains. A recent refinement is that ideas and values are the things that are deliberated over, whereas perspectives are the relevant properties of the people who are deliberating (Bohman, 2006). On this view, epistemic outcomes are optimized by maximizing the range of perspectives rather than maximizing the range of ideas or opinions, as perspectives are the source of variation in ideas.

Computational models simulate how group-level outcomes can depend on diverse perspectives or strategies. For instance, the 'Diversity Trumps Ability' thesis originates in a model (Hong \& Page, 2004) where simulated agents employ different strategies to discover the point of maximum value on an epistemic landscape. Each position on the abstract landscape represents an epistemic outcome, such as a different scientific discovery, research method, engineering design, or collective decision. The altitude of the position represents its epistemic value: the importance of the discovery, the efficiency of the design, or the accuracy of the decision. The challenge is to identify the peak with the highest epistemic value (the global optimum) without getting caught on local optima. Individual strategies vary in quality, each reaching points of different value. Crucially, a randomly selected group is more likely to find the optimal epistemic outcome than a group of experts - those whose individual strategies yielded the greatest individual gain (Hong \& Page, 2004).

Other models make similar claims based on a 'Division of Cognitive Labor' (Kitcher, 1990). In these models, some agents have a basic hill-climbing strategy and, individually, achieve good outcomes. Other agents tend to explore unfamiliar areas, and still others exploit familiar areas. The explorers frequently have poor individual outcomes, but their presence radically improves group outcomes (Thoma, 2015). Overall, diverse groups have the best outcomes (Pöyhönen, 2017, Thoma, 2015; Weisberg \& Muldoon, 2009).

One contribution of such models, then, is to undermine the intuition that a group of experts is always best, and to show how cognitive diversity produces a range of behaviors that leads to better problem solving. Further, they highlight how the best outcomes for an individual do not straightforwardly translate into the best outcomes for a group. In general, such models aid theory building (Guest \& Martin, 2021), though we note recent calls for 'empirically sensitive robustness' in simulation studies (Fazelpour \& Steel, in press).

Empirical evidence for the benefit of different judgments began with the 'Wisdom of Crowds' effect (Galton, 1907; Surowiecki, 2004). For instance, people estimated the weight of a bull, producing a range of guesses that, when aggregated, were close to the true value (Galton, 1907). There is some experimental support for aforementioned computational models. For instance, the Diversity-Trumps-Ability thesis was supported by a semester-long experiment where participants - running startup companies as part of a business course - were assigned to teams of either diverse or homogeneous cognitive ability. Diverse teams outperformed high-ability teams (Hoogendoorn, Parker, \& Van Praag, 2017).

Looking more broadly, there are two important pathways through which informational variation can have a positive effect on collective problem solving. In Wisdom-of-Crowds phenomena, where each person's estimate has some error, aggregating the group's opinions can reduce overall error. Call this the 'error-reduction' pathway. In phenomena like the Diversity-Trumps-Ability thesis, where no individual has all the information necessary to complete a task, the increased variety of information held by the group is needed 
to reach the optimal outcome (Williams \& O'Reilly, 1998). Call this the 'information-augmenting' pathway.

However, other studies find null or negligible effects of diversity. For instance, diverse crowds were no better than homogeneous ones at predicting the likelihood of global events in a Wisdom-of-Crowds study (de Oliveira \& Nisbett, 2018). Generally, meta-analyses of job performance frequently find small or null effects of diversity (Bell et al., 2011, Bowers, Pharmer, \& Salas, 2000, Eagly, 2016, Horwitz \& Horwitz, 2007; Van Dijk et al., 2012; Williams \& O'Reilly, 1998). Even in cases where there are benefits, those benefits may fail to materialize in group outcomes unless various practical conditions are met (Paulus, van der Zee, \& Kenworthy, 2019).

Thus, even though normative and computational accounts propose benefits of diversity, empirical studies offer considerably less support. One aspect of the Diversity Gap is that the promise of diversity frequently fails to materialize in reality. Another is that the benefits may be outweighed by various costs. The focus in the literature thus far has been on why, how and whether diversity has an epistemic benefit, but genuine progress on this issue needs a better theoretical understanding of when. When are the benefits clearest and when should we not expect to see any? When are the costs genuine, and when incidental?

\section{Null effects are common, but are not a mark against diversity}

If the promised benefits of diversity sometimes fail to materialize, is this because they don't exist, or because we are looking in the wrong places? Not all epistemic tasks are equally likely to benefit from informational diversity. In a task where there is no reason to expect diversity to help, a null effect does not have much to teach us about the value of diversity. To illustrate: nobody would expect an effect of diversity on the outcomes of people playing a fixed number of games on a row of identical slot machines. If one studied the effects of diversity on slot machine outcomes (or the epistemic analogue) and found no benefit of diversity, then this result would be less a failure of diversity, and more an artifact caused by a paradigm ill-suited to testing the effects of diversity.

What tasks can benefit from diversity? Our first conjecture is that diversity is useful for problem solving. To the extent that a task does not require problem solving, then, an empirical null result is more like the slot-machines example, and thus does not meaningfully undermine the promise of diversity. A problem exists when one has a goal to attain, but one does not have an existing strategy or sufficient information, and one must work out how to get from one's current state to one's goal state (Frensch \& Funke, 1995). This technical sense excludes cases where the strategy exists because it is innate (e.g., many animal behaviors), or because one has previously learned which strategy to apply (e.g., doing long division). Scientific inquiry is a clear example of problem solving, but problems also occur in many other occupations (Van Knippenberg \& Schippers, 2007). However, 'problem' need not be a binary category - something can be more or less of a problem, depending, for instance, on how accessible the strategy is.

Empirical studies confirm that this basic distinction is important. A meta-analysis of job performance (Van Dijk et al. 2012) found that the positive effect of diversity was stronger when a particular task was out-of-role (thus less familiar or more novel, requiring problem solving) than when the task was in-role (thus routine, with a familiar strategy, and not a problem in the technical sense above). Similarly, a stronger benefit of immigration or demographic diversity is found for jobs that involve problem solving than for those that do not (Cooke \& Kemeny, 2017). Thus, a preliminary explanation of the Diversity Gap is that null effects may be driven by studying performance generally, rather than the problemsolving aspects of performance in particular.

Compare two superficially similar Wisdom-of-Crowds studies (de Oliveira \& Nisbett, 2018, Pescetelli, Rutherford, \& Rahwan, 2020). Both posed questions that could not be answered with certainty (e.g., 'Before 1 August 2018, will the Moroccan government and the Polisario Front meet for official negotiations over Western Sahara?', Pescetelli et al., 2020). de Oliveira and Nisbett found no benefit of diversity, whereas Pescetelli et al. found a benefit in larger groups. This seeming contradiction is an instance of the Diversity Gap.

A crucial difference is that participants in Pescetelli et al. (2020) could do their own research online before answering. They could engage in problem solving, so there was a clear pathway through which individual differences in exploration strategies could meaningfully contribute to group-level aggregate beliefs. A similar benefit of diversity exists in other studies where such a pathway is present (Bhatt et al. 2017).

de Oliveira and Nisbett (2018) admit that there must be variation in information if diversity is to have an effect, but their design limited participants' contributions to their prior knowledge. Participants were given questions that many would not know the answer to, so what should they do but guess? Such a task focuses on the error-reduction pathway rather than the information-augmenting pathway, but error reduction - like the slot-machines example — does not require cognitive diversity. For instance, in a model of ant foraging, random variation in behavior and subsequent pooling was sufficient to produce a Wisdom-of-Crowds effect even though individuals were cognitively identical (Sasaki, Granovskiy, Mann, Sumpter, \& Pratt, 2013). Thus, if a particular Wisdom-of-Crowds task does not involve problem solving, it is not a good place to look for a benefit of diversity.

Problem solving is a process, thus involving multiple subparts (Watson, Kumar, \& Michaelsen, 1993), including both 
divergent and convergent processing (Paulus et al. 2019). Thus, a focus on single-step tasks may also contribute to the Diversity Gap. To illustrate: let's say factor X helps people do better at task type $\mathrm{A}$ and factor $\mathrm{Y}$ helps them do better at task type B. If a study looks at the effects of having both $\mathrm{X}$ and $\mathrm{Y}$ in just one task type - as is common in the literature - it may fail to find a benefit of diversity. But genuine problems often comprise multiple subtasks. If $\mathrm{A}$ and $\mathrm{B}$ are part of some larger undertaking, then diversity of Xs and Ys will produce a benefit for that broader goal. In that case, the lack of benefit found in a single-task study would be misleading. Scientific inquiry has multiple subparts (e.g., discovering new things vs. showing that findings replicate). Diversity should thus be crucial overall if scientists are to produce work that is both novel and replicable (Devezer, Nardin, Baumgaertner, \& Buzbas, 2019).

\section{What types of informational diversity are likely to be useful}

We have highlighted when diversity is beneficial - that is, for problem solving. Are we then better placed to see how it does so? The seminal Diversity-Trumps-Ability result (Hong \& Page, 2004) is concerned with cognitive ability. However, subsequent developments with both agentbased simulations (Pöyhönen, 2017; Thoma, 2015, Weisberg \& Muldoon, 2009) and human participants (Aggarwal, Woolley, Chabris, \& Malone, 2019; Basadur \& Head, 2001; Mello \& Rentsch, 2015) have instead found diversity in cognitive style to be an important predictor of problem-solving performance. Cognitive style refers to consistent individual differences in how people tend to represent and approach problems, such as being more analytic or intuitive, visual or verbal, novelty-seeking or tradition-bound (Kozhevnikov, Evans, \& Kosslyn, 2014; Roebuck \& Lupyan, 2020). In an explicit comparison of diversity in ability vs. style, the latter was found to be a better predictor of performance, so thinking differently can be more important than thinking better (West \& Dellana, 2009).

Why does cognitive style diversity matter for problem solving? First, cognitive style mediates the effect of cognitive ability on epistemic outcomes, since it is the semistable, semi-flexible intermediary between stable traits (such as intelligence or working memory capacity) and temporary problem environments (Viator, Harp, Rinaldo, \& Marquardt 2019). For instance, people with a more spatial-visualization style (vs. object-visualization style) were more likely to identify what sub-tasks needed to be done within a larger navigation and identification task, which improved accuracy (Aggarwal \& Woolley, 2013).

Second, in an epistemic landscape, two components are critical to group success: climbing an already-discovered hill to evaluate its epistemic value, and exploring undiscovered areas to locate new hills. Diversity of style (some individuals preferring to strike out for unexplored areas, others preferring to exploit known areas) is essential for groups to do well overall (Pöyhönen, 2017, Thoma, 2015, Weisberg \& Muldoon 2009).

Additionally, diversity of values is a crucial aspect of many explore/exploit tasks (Thoma, 2015). Exploration of the landscape is costly and risky (Boyd, Richerson, \& Henrich, 2011), and explorers on average make few individual gains (Thoma, 2015). However, if reward is tied to individual performance, agents are unlikely to risk exploring alternatives (Mann \& Helbing, 2017). Yet exploration of the landscape is crucial for optimal group epistemic progress (Pöyhönen, 2017). Thus, for the group to benefit from diverse strategies, either explorers have to be motivated by something other than individual success (such as finding novelty intrinsically valuable), or there must be concomitant diversity of rewards. For instance, scientists who bridge previously unrelated research topics get fewer citations on average, but are more likely to win prestigious academic prizes (Foster, Rzhetsky, \& Evans, 2015).

Reward is not the only sense of 'value' relevant here: scientists have different notions of what makes a theory or explanation valuable (Kuhn, 1977). If some scientists are interested in theories that are simple and others in theories that are fruitful, this diversity of values may improve overall scientific progress (though empirical research on this is thin on the ground). Further, the distinction between these epistemic values and more social values is not always clearcut, and variation in such values can be related to demographic differences such as gender (Longino, 1995). Given that gender diversity can make for better science (Campbell et al. 2013), diversity of values may be a possible concrete mechanism by which this occurs (Longino, 2002; Nielsen, Bloch, \& Schiebinger, 2018).

\section{When interactional costs arise, they are often not inherent to diversity}

When people interact, dissimilarity is associated with increased conflict, worse communication, or lower satisfaction (De Dreu \& Weingart, 2003; Mannix \& Neale, 2005, Stahl et al., 2010, Van Knippenberg et al., 2004; Williams \& O'Reilly, 1998). Demographic features are salient inputs to social categorization processes, so people may prefer to associate with and learn from those who are more similar to them, or be less willing to trust those who are dissimilar (Mannix \& Neale, 2005; Van Knippenberg et al., 2004, Williams \& O'Reilly, 1998). This is not limited to demographic diversity: congruence of cognitive style influences people's choice of who to learn from (Hunt, Krzystofiak, Meindl, \& Yousry, 1989), and diversity in cognitive style negatively impacts consensus formation (Aggarwal \& Woolley, 2013) and lowers satisfaction (Basadur \& Head, 2001).

Thus, interactional costs may outweigh the benefits of in- 
formational diversity (Galinsky et al., 2015, Van Knippenberg et al. 2004). This occurs even in science: demographic minorities are more likely to make novel connections between concepts, but their ideas are less likely to be taken up by the demographic majority (Hofstra et al. 2020) or to make it past reviewers (Murray et al. 2019).

To understand the Diversity Gap, we need to know when such costs are caused by diversity specifically, vs. when they are due to aspects of the interactional context that can affect the flow of information, but that can vary independently of diversity, such as social norms or individual motivations (Paulus \& Brown, 2007).

Costs frequently occur in fields with unbalanced representation (e.g., when a field is dominated by white males), whereas in fields with more balanced representation, demographic diversity can have a more positive effect on group outcomes (Joshi \& Roh, 2009). Further, costs of demographic diversity are reflected in subjective ratings of performance, but these costs are ameliorated when performance is measured more objectively(Van Dijk et al. 2012 I] Even when diverse groups outperform homogeneous groups, they can report lower confidence in their performance (Phillips, Liljenquist, \& Neale, 2009) or lower liking of their group (McLeod, Lobel, \& Cox 1996).

Thus, it is often the 'context' part of 'interactive context' that is the problem (Joshi \& Roh, 2009, Mannix \& Neale. 2005), and it is there that solutions must be sought. For instance, these costs can be ameliorated by changes in culture, organization-, or group-level values and policies (Bell et al., 2011;: McLeod et al., 1996), fostering diversity mind-sets (Van Knippenberg \& Schippers 2007) or a common identity that does not obscure individual differences (Crotty \& Brett, 2012, Salazar, Feitosa, \& Salas, 2017).

One such change is pro-diversity messaging or attitudes (Paulus et al. 2019). For instance, gender-diverse groups who had been told that diversity would be beneficial in solving a problem outperformed groups who had been told that homogenous groups would be advantaged (Homan, Van Knippenberg, Van Kleef, \& De Dreu. 2007), and prodiversity messaging can help close the gap between performance of demographic minorities and majorities (Murrar, Campbell, \& Brauer, 2020). Similarly, as perspective taking is one practical condition for the benefits to be realized (Paulus et al. 2019), diversity has a more positive effect on team creativity when there is team-external motivation to engage in perspective taking (Hoever, Van Knippenberg, Van Ginkel, \& Barkema, 2012).

As the effects of such policies may be limited by persistent individual bias (Galinsky et al., 2015), exposure to diversity earlier in development (e.g., at school) may ameliorate some negative outcomes. Indeed, results from the Program for International Student Assessment (PISA) show that demographic diversity at school has a positive effect on collective problem solving (Graesser et al., 2018).

These lines of evidence suggest that this aspect of the Diversity Gap - when costs seem to outweigh benefits - is really two problems in one. The first is really more of a 'Diversity Hump': the inclusion of demographic minorities or those with very different ideas may initially be met with negative interactional outcomes. But this is not an argument against the benefits of diversity, as once this hump is passed and the context itself becomes diverse, the gap is substantially reduced (Hoogendoorn \& Van Praag. 2012). Indeed, as societies grow more diverse, people perceive others as more similar (Bai, Ramos, \& Fiske, 2020).

The second is more a matter of implementation. Even once the diversity hump is passed, there are still a number of practical conditions that should be met, to allow the benefits of diversity to actually impact the group collaborative outcome. In addition to the pro-diversity attitudes and motivations for perspective taking mentioned above, these include having enough experience working together as a team, and a safe climate (Paulus et al. 2019). Nonetheless, the cognitive, social and motivational factors may be hard to disentangle (Paulus \& Brown, 2007).

Such implementational issues aside, the core message here is that the contextual costs are all too often exacerbated by homogeneity, rather than caused by diversity (Apfelbaum, Phillips, \& Richeson, 2014). But why frame it in this way, rather than just treating context as moderating the relationship between diversity and outcome (as is all too common in the literature)? We feel that treating context as a moderating factor seriously mischaracterizes the problem. It is analogous to claiming that queer-bashing is a consequence of homosexuality, and that homophobia is a moderating variable. Doing so is wrong. Calling it 'moderation' either misplaces the cause of the problem if meant literally, or at least obscures the cause if meant as a statistical shorthand. Although this is perhaps more obvious in our analogy than it is in the literature on diversity, the principle is the same.

\section{Interactional costs sometimes have epistemic benefits}

A further reason not to frame these as interactional costs inherent to diversity is that the same processes can also yield epistemic benefits. Communication can be maladaptive if conformity leads the majority of a group to converge on a suboptimal outcome, yielding herding or groupthink (Lorenz, Rauhut, Schweitzer, \& Helbing, 2011; Stahl et al., 2010, Toyokawa, Whalen, \& Laland, 2019, Weatherall \& O'Connor, 2020; Zollman, 2010). Thus, it can sometimes be epistemically useful if communication is disrupted.

If diversity in an interactive context is met with distrust,

\footnotetext{
${ }^{1}$ We note that the same study showed that objective (vs. subjective) measures also weaken the benefit of diversity, but they remain significant and positive in any case.
} 
this can reduce herding, yielding epistemic benefits. For example, beliefs were better calibrated for diverse groups than for homogeneous groups in an experimental stock-market task, where people had to gauge the value of some commodities (Levine et al. 2014), and in a murder-mystery task where people had to gather and evaluate evidence (Phillips et al. 2009). While distrust can slow the spread of information, it can also slow the spread of pernicious misinformation (Fazelpour \& Steel, in press). It is not even necessary that this effect be driven by distrust, as homogeneity can make people less aware that different perspectives exist (Apfelbaum et al., 2014). Given that different perspectives do exist, focusing on diversity can in fact improve communication (Todd, Hanko, Galinsky, \& Mussweiler. 2011).

Several mechanisms explain these benefits. For one, errors are more correlated both for homogeneous groups (Levine et al. 2014) and for communicating groups (Hahn, von Sydow, \& Merdes, 2019), so heterogeneity and breakdowns in communication can both prevent correlated errors from dominating group decisions. Diversity lowers people's drive to conform (Gaither, Apfelbaum, Birnbaum, Babbitt, \& Sommers, 2018), whereas as a pressure to conform creates a disconnect between what people publicly say and what they believe (Weatherall \& O'Connor, 2020). Diverse contexts can also increase people's evaluation of the uniqueness of their own information (Phillips, Northcraft, \& Neale, 2006), and increase their perceptions of tolerance of dissenting viewpoints (Phillips \& Loyd, 2006).

However, our account does not explain away all interactive costs: if people have genuinely different perspectives, it is hard to reach an integrative understanding (Cronin \& Weingart, 2007). This takes effort and time to overcome (Paulus et al., 2019; Watson et al. 1993). In that case, it is particularly salient that diversity plays a double role. Not only does it increase the range of information brought to problem solving (Galinsky et al., 2015: McLeod et al., 1996; Sommers, 2006; Williams \& O'Reilly, 1998), but it can also improve people's ability to consider or integrate this range of information. The synergistic effect is that diversity provides diverse perspectives, and also promotes perspective taking (Antonio et al., 2004, Maddux, Adam, \& Galinsky, 2010, Nemeth \& Wachtler. 1983; Tadmor, Tetlock, \& Peng, 2009. Todd et al. 2011). This may occur because diversity can increase people's tendency to process information more deeply (De Dreu, Nijstad, \& van Knippenberg, 2008, Galinsky et al. 2015), divergently (Nemeth, 1995) or abstractly (Tylén, Fusaroli, Smith, \& Arnoldi. 2020); it can raise their tolerance of ambiguity and open-endedness (Tadmor et al., 2009); and it can increase their openness to diversity (Chang, Denson, Saenz, \& Misa, 2006).

Given that there are limits on the extent to which group- or organization-level policies can effect behavior change, learning to acknowledge differences in perspectives Apfelbaum et al., 2014) and engage with those perspectives (Galinsky et al. 2015) are important aspects of closing the Diversity Gap. Perspective taking is a further way in which demographic diversity can interact with cognitive diversity to boost group outcomes. For instance, the proportion of women in a group positively predicted group problem solving, and this effect was mediated via increased levels of social perceptiveness (Woolley, Chabris, Pentland, Hashmi, \& Malone, 2010).

\section{Diversity in social learning strategies resolves an underlying tension}

Collective problem solving involves a fundamental tension: the same factor - communication - pulls in opposite directions. The benefit is that social learning spreads information necessary to solve a particular problem; the cost is that this simultaneously reduces both the informational diversity in the group (Lazer \& Friedman, 2007) and the group's tendency to find new information (Yahosseini, Reijula, Molleman, \& Moussaïd 2018). Social learning can also cause a group to converge on something because it is popular, rather than because it is good, making outcomes increasingly unpredictable (Salganik, Dodds, \& Watts, 2006).

This cost arises, in part, because human cognition is not geared towards sharing the most epistemically useful information. People amplify information that is already public, even if they hold private information that is more useful for the problem (Gigone \& Hastie, 1993; Stasser \& Titus, 1985). Further, people choose who to get their information from based on factors that are - at best - noisily related to the value of their information such as prestige (Henrich $\&$ Gil-White, 2001) or popularity (Salganik et al., 2006) or - worse - are orthogonal such as the desire to boost social affiliation (Cialdini \& Goldstein, 2004).

People differ in how much they use social information when making decisions or solving problems (Efferson, Lalive, Richerson, McElreath, \& Lubell, 2008, Mesoudi, Chang, Dall, \& Thornton, 2016, Molleman, Kurvers, \& van den Bos, 2019), with some being more independent and others more conformist. However, given that social information can have both positive and negative effects, it follows that neither heavy use of social information nor avoidance of social information are likely to be universally successful strategies (Laland, 2004). Overall, intermediate levels of connectedness can maximize a society or culture's ability to evolve (Derex, Perreault, \& Boyd, 2018).

Thus, we propose that diversity in social information use is an important mechanism whereby diversity benefits collective problem solving. There are computational models showing that diversity in social information use is beneficial for epistemic outcomes, with most individuals being rather conformist, but some more maverick (Pöyhönen, 2017, Thoma, 2015). Again, though, these benefits may only accrue in certain situations (Sulik, Bahrami, \& Deroy, 2021), and as this 
represents a major gap in the experimental literature, one avenue for further research is whether this factor has a wider effect.

\section{Better models are needed to weigh benefits vs. costs}

As there are both benefits and costs (whether inherent or incidental), neither total homogeneity nor maximal diversity are likely to be optimal. Indeed, there is frequently a curvilinear relationship — specifically, an inverted U-shape (Fig. 1a) - between diversity and epistemic outcomes (Aggarwal et al., 2019, Basadur \& Head, 2001; Curşeu, Schruijer, \& Boroş, 2007; Dahlin, Weingart, \& Hinds, 2005; Derex et al., 2018, Hoogendoorn \& Van Praag, 2012, Lazer \& Friedman, 2007; Mannix \& Neale, 2005; Monechi, Pullano, \& Loreto, 2019; Van Knippenberg \& Schippers, 2007; Williams \& O’Reilly, 1998).

This implies a pressure towards moderate diversity. However, it is an intuition trap to think that this pattern is driven by the presence of both benefits and costs. This intuition does not explain the curvilinear pattern, because it is compatible with a wide range of overall outcomes (Busse, Mahlendorf, \& Bode, 2016). All scenarios in Fig. 1] involve both costs and benefits, but vary in their overall patterns. Thus, the mere existence of costs and benefits is not enough to create an overall pressure in any direction.
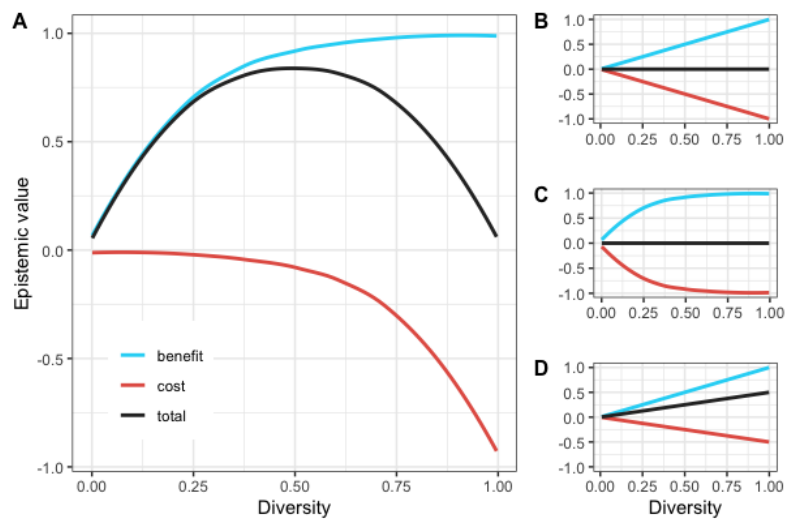

Figure 1. Schematic representations of the costs and benefits of diversity, and the total outcome (the sum of the cost and benefit values), all represented on an arbitrary unit scale. (a) Costs and benefits have nonlinear relationships with diversity, and the curves are not symmetric about $\mathrm{y}=0$, yielding an inverted- $U$ pattern. (b) Costs and benefits change linearly and symmetrically, yielding no overall pressure. (c) Both change non-linearly and symmetrically, also yielding no overall pressure. (d) Both change linearly, but the benefit slope is larger, yielding an overall pressure towards high diversity.

Overall pressures depend on the specific shapes of the relevant cost/benefit functions (Busse et al., 2016, Grant \& Schwartz, 2011). If costs and benefits are symmetric about the $x$-axis (Fig. $1 \mathrm{p}, \mathrm{c}$ ), the net outcome is flat: there is no pressure either towards high or low diversity. If the relationships are not symmetric, this can produce an overall pressure towards either high or low diversity (Fig.11 d). For an inverted-U pattern, costs and benefits must be asymmetric, and at least one must be nonlinear (e.g., a benefits curve that initially increases steeply and then plateaus, and a cost curve that does the opposite, Fig. 19).

In applied approaches to diversity, theoretical models are frequently represented as chains of causal relationships that have either positive or negative effects. However, as Fig. 1 demonstrates, just knowing if an effect is positive or negative is insufficient to explain the presence or absence of pressures towards low, moderate or high diversity. Thus, for progress to be made on the Diversity Gap, better theoretical models are needed, including parameters for curve shapes (Grant \& Schwartz, 2011). Articulating such relationships more clearly is one benefit of computational models (Guest \& Martin, 2021).

This is not merely a matter for theory, but also has practical implications. For instance, if it turns out that the benefits of diversity tail off (or the costs grow steeper) for larger groups (Cummings, Kiesler, Bosagh Zadeh, \& Balakrishnan, 2013), then this captures one source of the problem and highlights where potential solutions may be sought. For instance, if communication is especially difficult for larger diverse groups, the large groups could be restructured so that problems are tackled by smaller subgroups (e.g., Navajas, Niella, Garbulsky, Bahrami, \& Sigman, 2018.

However, the particular challenge this raises for the Diversity Gap is that it is not enough to know when diversity offers epistemic benefits. Rather, it is important to know when such benefits climb steeply enough, relative to costs, so as to produce an overall pressure away from low diversity.

\section{A more nuanced view of problem solving: complexity matters}

Our initial claim was that diversity is beneficial for collective problem solving (and not necessarily for epistemic performance generally), but this glossed over a key factor: the benefits of diversity are stronger for more complex problems (Bosetti et al., 2012, Bowers et al. 2000, Cooke \& Kemeny, 2017; De Dreu et al. 2008; Grim et al. 2019; Hong \& Page, 2001, LiCalzi \& Surucu, 2012; Page, 2014, Pöyhönen, 2017; Van Dijk et al., 2012; Yahosseini \& Moussaïd, 2019). 'Without diversity, one cannot have much complexity. But without complexity, diversity becomes mere variation, noise about the mean' (Page, 2014, p 268).

Thus, problem complexity can affect the shapes of the aforementioned cost-benefit curves to yield an overall pressure for higher diversity. But what does 'complexity' mean, and how do different definitions contribute to the benefits of diversity? There are three broad approaches to complexity as moderating the effects of diversity: (i) informal approaches, 
(ii) approaches based on computational complexity, and (iii) approaches rooted in the empirical problem-solving literature.

As an example of an informal approach, 'complexity' in Horwitz and Horwitz (2007) is used to distinguish project work from service or manufacturing work. However, there are no clear reasons why project work should count as particularly complex in any useful or important sense, or why this is not merely 'difficulty'. It is thus hard to know what to make of their null results, whereas the following alternatives both offer theoretical frameworks to decide what counts as complex.

Computational approaches offer quantifiable measures of problem complexity. Problems are characterized by sets of parameters or inputs and corresponding solution outputs. Different classes of complexity depend on the kind of function maps these inputs to the computational run-time required by an algorithm to produce the outputs (Van Rooij. 2008). For instance, if $i$ represents some measure of the size of a problem space to be searched and $a$ represents some constant, then a problem-solving algorithm whose run-time is a function of $a^{i}$ is more complex than one whose run-time is a function of $i^{a}$, because the former value grows much faster than the latter as $i$ increases.

Frequently, computational complexity in problem solving is cashed out in terms of a rugged epistemic landscape, where individuals are likely to get stuck on local optima, but where the global optimum is hard to find (Alexander, Himmelreich, \& Thompson, 2015; Almaatouq, Yin, \& Watts 2020, Bernstein, Shore, \& Lazer, 2018; Lazer \& Friedman 2007, Yahosseini \& Moussaïd. 2019). Experimental results in complex problem solving show that when communication is throttled, this reduces herding and maintains informational diversity, thus preventing people from converging on local optima, and boosting the group's chances of discovering the global optimum (Bernstein et al. 2018, Shirado \& Christakis, 2017).

In contrast, the problem-solving literature has not agreed on just what defines a complex problem. It offers several candidate dimensions (Frensch \& Funke, 1995), but these only have a family resemblance between them (Sternberg, 1995).

One such dimension is novelty (Dörner \& Funke, 2017, Frensch \& Funke, 1995). The Diversity Gap should be narrower for novel problems, which require some creativity, and wider for problems that people are familiar with, such as their routine jobs. Creative or innovative tasks are those where diversity consistently has a positive effect (Basadur \& Head, 2001, Bell et al., 2011, Bowers et al., 2000, Galinsky et al. , 2015; Hoever et al., 2012; Leung \& Chiu, 2010 Mannix \& Neale, 2005; Mello \& Rentsch, 2015; Parrotta, Pozzoli, \& Pytlikova, 2014; Paulus, van der Zee, \& Kenworthy, 2016; Polzer, Milton, \& Swarm Jr, 2002, Stahl et al., 2010; Van Dijk et al., 2012; Wang, Cheng, Chen, \& Le- ung, 2019, Williams \& O'Reilly, 1998). Relatedly, collective problem solving requires not only that individuals bring a variety of information to an interaction, but also that these pieces of information recombine in novel ways during interaction: 'new ideas are born at the social nexus where previously isolated ideas meet' (Muthukrishna \& Henrich, 2016. p 5). This is also a prime example of where diversity in demographic factors such as ethnicity (McLeod et al., 1996) and gender (Schruijer \& Mostert, 1997) or both (Hofstra et al., 2020) improve group-level outcomes. For instance, even if diversity on a company board does not positively predict profits (Eagly, 2016), it can still predict innovation (Bernile, Bhagwat, \& Yonker, 2018, Parrotta et al., 2014). Even then, implementational factors such as experience together or time spent reflecting will affect whether the creative benefits of diversity actually materialize (Paulus \& Brown, 2007; Paulus et al. 2019).

A second dimension of problem-solving complexity is the distance between people and their goals (Dörner \& Funke, 2017, Frensch \& Funke, 1995). If one's goal involves a solving complex sequence of problems, these are likely to vary in their requirements, and are thus likely to benefit from diversity. However, if the goal requires just a single step, then there is less scope for diversity to play a role. This is one reason why we previously emphasized that problem solving is a process, and why single-step Wisdom of Crowds tasks are unlikely to be a reasonable place to search for an effect of diversity.

Other dimensions of problem complexity center on 'Representational Complexity'. In a recent study of realworld problem solving, researchers probed participants' representations of the various problem components and the causal relationships connecting those components, and then used these to construct graphical knowledge maps (Aminpour et al. 2021). The individuals had different stakes in the problem, and thus had different perspectives on what mattered and how it mattered. The aggregated knowledge maps of diverse groups were shown to be more accurate than those of homogeneous groups.

This illustrates how diversity affords representational complexity, but it does not yet demonstrate that representationally complex problems are when diversity is most likely to be epistemically useful or, in terms set out above, to produce especially steep benefits curves. To address this 'when?' question, diversity research needs better understanding of (and subsequently, measurement of) the specific dimensions that contribute to representational complexity.

One such dimension is opacity (Dörner \& Funke, 2017, Frensch \& Funke, 1995; Gergely \& Csibra, 2006) since, for simple problems, it is easy to discern or evaluate the current problem state (i.e., the values of relevant variables, and the causal relationships between them), whereas for more opaque problems, these states, values or relationships 
must be hypothesized. Another, related dimension is relevance or selective encoding (Kwisthout, 2012, Sperber \& Wilson, 1995, Sternberg, 1995). Sometimes it is comparatively obvious what information is relevant for a problem, and sometimes this must be inferred. Such inferences are notoriously intractable in the general case (Fodor, 2001; Kwisthout 2012), and are related to creative hypothesis generation (Blokpoel, Wareham, Haselager, Toni, \& van Rooij 2018, Sulik, 2018).

Both aspects of representational complexity offer concrete mechanisms that lie at the nexus of several factors raised above, such as variation in perspectives, problem representations, and creativity. For instance, the relevance dimension is foundational for pragmatics, the aspect of communication that involves understanding people's perspectives and intentions in context (Sperber \& Wilson, 1995), and perspectivetaking is hard (Sulik \& Lupyan, 2018), partly because it is cognitively opaque (Gergely \& Csibra, 2006). In turn, shifts in perspective are central to group creativity (Hoever et al. 2012) and to insightful problem-solving, where solving a problem explicitly requires a shift in problem representations (Beeman, 1993, Bowden \& Jung-Beeman, 1998, Sulik 2018).

As opacity and relevance are both under-explored in the diversity literature, we can only speculate about their role. We predict that the Diversity Gap will be wider when people are simply given hypotheses to evaluate, along with the necessary data, and narrower when people must generate their own hypotheses, or find and gather their own data. Similarly, we predict that the Diversity Gap will be wider when there is general consensus about what information might be relevant to solving a problem or about how to represent the problem, and narrower when relevance presents a challenge, or when the relevant problem representation is non-obvious, or when the obvious representation is misleading. The last two features characterize 'insight problems' (Bowden \& JungBeeman, 1998, Durso, Rea, \& Dayton, 1994; Gilhooly \& Murphy, 2005), so this class of problems represents an important avenue for future research on closing the Diversity Gap.

\section{Diversity needs an inclusive sense of 'complexity'}

Only one experiment (to the best of our knowledge) has studied the effect of diversity on problem solving while varying complexity, and it found no interaction between diversity and complexity (Almaatouq et al., 2020). However, it varied only computational complexity, so it does not undermine the promise of diversity for complex problem solving. Instead, we need an inclusive approach that incorporates both computational and representational complexity.

Representational complexity is logically prior to computational complexity, which assumes that some degree of abstraction has already taken place, a problem representation has been chosen, and the information relevant to solving the problem has been identified (Kwisthout, 2012). Problem solving often starts prior to this point, because deciding what information may be relevant to solving the problem is often part of the problem, and the same is true for deciding how to represent the problem. Similarly, whereas the computational complexity approach assumes a well-defined solution state, real-world complex problem solving often involves ill-defined solution states (Dörner \& Funke, 2017). Finally, computational complexity is mathematically formalized, whereas relevance and hypothesis generation are notoriously hard to formalize (Fodor, 2001; Reichenbach, 1938).

Thus, we propose that representational complexity is crucial for problem posing, problem construction or hypothesis generation. This is one of the biggest gaps in diversity research, and thus offers the potential for a transformational leap forward. Although one genuine cost of informational diversity is that it can impede consensus formation, consensus is not important for all stages of problem solving (Basadur \& Head, 2001), especially not for the initial stages of the process highlighted here.

In sum, representational complexity (and its role in problem posing) can complement analytic computational approaches to well-defined problems. Focusing exclusively on either approach in isolation can contribute to the Diversity Gap, because both approaches are in fact integral to complex problem solving more broadly construed. As science is a complex undertaking in both senses of 'complex', the issues raised here illustrate why there is a need for diversity in science. For instance, diversity can affect what research questions are generated, or what alternative hypotheses are considered (Intemann, 2009).

\section{Conclusions and future directions}

The benefits of diversity obtain most clearly in complex problem solving, rather than performance in general. In particular, they depend on an inclusive or enhanced sense of 'complex', one that can account for the importance of creativity and problem posing, and the role that diverse cognitive styles, perspectives and values can play in these.

Throughout, we have been mentioning results from, and implications for, doing science. Science is a prime example of a complex problem, in many senses covered here. It comprises multiple and various subtasks; it involves a rugged epistemic landscape; and frequently includes conflicting perspectives, creativity and problem posing. It also highlights how the promise of diversity can be diminished by institutional or individual bias. The role of diversity in science reflects in microcosm the role of diversity in general.

Our focus has been on how diversity affects problem solving, but what about the reverse? Given that humans display cognitive diversity, what was it about the ancestral human environment - and specifically what sorts of problems were 
our ancestors faced with - that made cognitive diversity an adaptive evolutionary strategy for our species? Fields such as anthropology, cultural psychology and cultural evolution have made a start on this problem, by arguing that cognition itself is culturally variable (Bender \& Beller, 2016), that we have brains evolved for both social norms and variability (Muthukrishna \& Henrich, 2016), that ecological factors contribute to a society's tolerance for deviation from such norms (Gelfand, Harrington, \& Jackson, 2017, Gelfand et al. 2011), and that diversity in personality increases in response to socioecological complexity (Lukaszewski, Gurven, von Rueden, \& Schmitt, 2017; Smaldino, Lukaszewski, von Rueden, \& Gurven, 2019).

We have highlighted several types of cognitive diversity (e.g., in values and cognitive style, including variation in social-information use) that are comparatively rare in the literature on diversity and problem solving, but another important avenue for research is the benefits of neurodiversity in this regard (and answers to the previous question on evolution may also speak to this question). There have been arguments for the value of neurodiversity in the workplace (e.g. Krzeminska, Austin, Bruyère, \& Hedley, 2019), but as yet, we know of no studies of the specific mechanisms whereby neurodiversity benefits collective problem solving.

\section{References}

Aggarwal, I., \& Woolley, A. W. (2013). Do you see what I see? The effect of members' cognitive styles on team processes and errors in task execution. Organizational Behavior and Human Decision Processes, 122(1), 9299.

Aggarwal, I., Woolley, A. W., Chabris, C. F., \& Malone, T. W. (2019). The impact of cognitive style diversity on implicit learning in teams. Frontiers in Psychology, $10,112$.

Alexander, J. M., Himmelreich, J., \& Thompson, C. (2015). Epistemic landscapes, optimal search, and the division of cognitive labor. Philosophy of Science, 82(3), 424453.

Almaatouq, A., Yin, M., \& Watts, D. J. (2020). Collective problem-solving of groups across tasks of varying complexity. PsyArXiv, January 29. doi: 10.31234/ osf.io/ra9qy

AlShebli, B. K., Rahwan, T., \& Woon, W. L. (2018). The preeminence of ethnic diversity in scientific collaboration. Nature Communications, 9(1), 1-10.

Aminpour, P., Gray, S. A., Singer, A., Scyphers, S. B., Jetter, A. J., Jordan, R., ... Grabowsky, J. H. (2021). The diversity bonus in pooling local knowledge about complex problems. Proceedings of the National Academy of Sciences, 118(5), e2016887118.

Antonio, A. L., Chang, M. J., Hakuta, K., Kenny, D. A., Levin, S., \& Milem, J. F. (2004). Effects of racial diversity on complex thinking in college students. Psychological Science, 15(8), 507-510.

Apfelbaum, E. P., Phillips, K. W., \& Richeson, J. A. (2014). Rethinking the baseline in diversity research: Should we be explaining the effects of homogeneity? Perspectives on Psychological Science, 9(3), 235-244.

Bai, X., Ramos, M. R., \& Fiske, S. T. (2020). As diversity increases, people paradoxically perceive social groups as more similar. Proceedings of the National Academy of Sciences, 117(23), 12741-12749.

Barrett, H. C. (2020). Towards a cognitive science of the human: Cross-cultural approaches and their urgency. Trends in Cognitive Sciences.

Basadur, M., \& Head, M. (2001). Team performance and satisfaction: A link to cognitive style within a process framework. The Journal of Creative Behavior, 35(4), 227-248.

Beeman, M. (1993). Semantic processing in the right hemisphere may contribute to drawing inferences from discourse. Brain and Language, 44, 80-120.

Bell, S. T., Villado, A. J., Lukasik, M. A., Belau, L., \& Briggs, A. L. (2011). Getting specific about demographic diversity variable and team performance relationships: A meta-analysis. Journal of Management, 37(3), 709-743.

Bender, A., \& Beller, S. (2016). Current perspectives on cognitive diversity. Frontiers in Psychology, 7, 509.

Bernile, G., Bhagwat, V., \& Yonker, S. (2018). Board diversity, firm risk, and corporate policies. Journal of Financial Economics, 127(3), 588-612.

Bernstein, E., Shore, J., \& Lazer, D. (2018). How intermittent breaks in interaction improve collective intelligence. Proceedings of the National Academy of Sciences, 115(35), 8734-8739.

Bhatt, S., Minnery, B., Nadella, S., Bullemer, B., Shalin, V., \& Sheth, A. (2017). Enhancing crowd wisdom using measures of diversity computed from social media data. In Proceedings of the international conference on web intelligence (pp. 907-913).

Blokpoel, M., Wareham, T., Haselager, P., Toni, I., \& van Rooij, I. (2018). Deep analogical inference as the origin of hypotheses. The Journal of Problem Solving, 11(1), 3 .

Bohman, J. (2006). Deliberative democracy and the epistemic benefits of diversity. Episteme, 3(2), 175-191.

Bosetti, V., Cattaneo, C., \& Verdolini, E. (2012). Migration, cultural diversity and innovation: a European perspective. (FEEM Working Paper) doi: 10.2139/ ssrn.2162836

Bowden, E. M., \& Jung-Beeman, M. (1998). Getting the right idea: Semantic activation in the right hemisphere may help solve insight problems. Psychological Science, 9(6), 435-440. 
Bowers, C. A., Pharmer, J. A., \& Salas, E. (2000). When member homogeneity is needed in work teams: A meta-analysis. Small Group Research, 31(3), 305327.

Boyd, R., Richerson, P. J., \& Henrich, J. (2011). The cultural niche: Why social learning is essential for human adaptation. Proceedings of the National Academy of Sciences, 108(Supplement 2), 10918-10925.

Busse, C., Mahlendorf, M. D., \& Bode, C. (2016). The ABC for studying the too-much-of-a-good-thing effect: A competitive mediation framework linking antecedents, benefits, and costs. Organizational Research Methods, 19(1), 131-153.

Campbell, L. G., Mehtani, S., Dozier, M. E., \& Rinehart, J. (2013). Gender-heterogeneous working groups produce higher quality science. PloS One, 8(10), e79147.

Chang, M. J., Denson, N., Saenz, V., \& Misa, K. (2006). The educational benefits of sustaining cross-racial interaction among undergraduates. The Journal of Higher Education, 77(3), 430-455.

Cialdini, R. B., \& Goldstein, N. J. (2004). Social influence: Compliance and conformity. Annual Review of Psychology, 55, 591-621.

Cooke, A., \& Kemeny, T. (2017). Cities, immigrant diversity, and complex problem solving. Research Policy, 46(6), 1175-1185.

Cronin, M. A., \& Weingart, L. R. (2007). Representational gaps, information processing, and conflict in functionally diverse teams. Academy of management review, 32(3), 761-773.

Crotty, S. K., \& Brett, J. M. (2012). Fusing creativity: Cultural metacognition and teamwork in multicultural teams. Negotiation and Conflict Management Research, 5(2), 210-234.

Cummings, J. N., Kiesler, S., Bosagh Zadeh, R., \& Balakrishnan, A. D. (2013). Group heterogeneity increases the risks of large group size: A longitudinal study of productivity in research groups. Psychological science, 24(6), 880-890.

Curşeu, P. L., Schruijer, S., \& Boroş, S. (2007). The effects of groups' variety and disparity on groups' cognitive complexity. Group Dynamics: Theory, Research, and Practice, 11(3), 187.

Dahlin, K. B., Weingart, L. R., \& Hinds, P. J. (2005). Team diversity and information use. Academy of Management Journal, 48(6), 1107-1123.

De Dreu, C. K., Nijstad, B. A., \& van Knippenberg, D. (2008). Motivated information processing in group judgment and decision making. Personality and Social Psychology Review, 12(1), 22-49.

De Dreu, C. K., \& Weingart, L. R. (2003). Task versus relationship conflict, team performance, and team member satisfaction: a meta-analysis. Journal of Applied
Psychology, 88(4), 741.

de Oliveira, S., \& Nisbett, R. E. (2018). Demographically diverse crowds are typically not much wiser than homogeneous crowds. Proceedings of the National Academy of Sciences, 115(9), 2066-2071.

Derex, M., Perreault, C., \& Boyd, R. (2018). Divide and conquer: Intermediate levels of population fragmentation maximize cultural accumulation. Philosophical Transactions of the Royal Society B: Biological Sciences, 373(1743), 20170062.

Devezer, B., Nardin, L. G., Baumgaertner, B., \& Buzbas, E. O. (2019). Scientific discovery in a modelcentric framework: Reproducibility, innovation, and epistemic diversity. PloS One, 14(5), e0216125.

Dörner, D., \& Funke, J. (2017). Complex problem solving: What it is and what it is not. Frontiers in Psychology, 8,1153 .

Durso, F. T., Rea, C. B., \& Dayton, T. (1994). Graphtheoretic confirmation of restructuring during insight. Psychological Science, 5(2), 94-98.

Eagly, A. H. (2016). When passionate advocates meet research on diversity, does the honest broker stand a chance? Journal of Social Issues, 72(1), 199-222.

Efferson, C., Lalive, R., Richerson, P. J., McElreath, R., \& Lubell, M. (2008). Conformists and mavericks: the empirics of frequency-dependent cultural transmission. Evolution and Human Behavior, 29(1), 56-64.

Fazelpour, S., \& Steel, D. (in press). Diversity, trust and conformity: a simulation study. Philosophy of Science.

Fodor, J. (2001). The mind doesn't work that way: The scope and limits of computational psychology. Cambridge, MA: MIT Press.

Foster, J. G., Rzhetsky, A., \& Evans, J. A. (2015). Tradition and innovation in scientists' research strategies. American Sociological Review, 80(5), 875-908.

Frensch, P. A., \& Funke, J. (1995). Definitions, traditions, and a general framework for understanding complex problem solving. In P. A. Frensch \& J. Funke (Eds.), Expertise in complex problem solving: A comparison of alternative conceptions. Lawrence Erlbaum Associates, Inc.

Gaither, S. E., Apfelbaum, E. P., Birnbaum, H. J., Babbitt, L. G., \& Sommers, S. R. (2018). Mere membership in racially diverse groups reduces conformity. Social Psychological and Personality Science, 9(4), 402410.

Galinsky, A. D., Todd, A. R., Homan, A. C., Phillips, K. W., Apfelbaum, E. P., Sasaki, S. J., ... Maddux, W. W. (2015). Maximizing the gains and minimizing the pains of diversity: A policy perspective. Perspectives on Psychological Science, 10(6), 742-748.

Galton, F. (1907). Vox populi. Nature, 75(7), 450-451.

Gelfand, M. J., Harrington, J. R., \& Jackson, J. C. (2017). 
The strength of social norms across human groups. Perspectives on Psychological Science, 12(5), 800809.

Gelfand, M. J., Raver, J. L., Nishii, L., Leslie, L. M., Lun, J., Lim, B. C., ... others (2011). Differences between tight and loose cultures: A 33-nation study. Science, 332(6033), 1100-1104.

Gergely, G., \& Csibra, G. (2006). Sylvia's recipe: The role of imitation and pedagogy in the transmission of cultural knowledge. In N. J. Enfield \& S. C. Levenson (Eds.), Roots of human sociality: Culture, cognition and human interaction (p. 229-255). Oxford: Berg Publishers.

Gigone, D., \& Hastie, R. (1993). The common knowledge effect: Information sharing and group judgment. Journal of Personality and Social Psychology, 65(5), 959974.

Gilhooly, K. J., \& Murphy, P. (2005). Differentiating insight from non-insight problems. Thinking $\mathcal{E}$ Reasoning, 11(3), 279-302.

Graesser, A. C., Fiore, S. M., Greiff, S., Andrews-Todd, J., Foltz, P. W., \& Hesse, F. W. (2018). Advancing the science of collaborative problem solving. Psychological Science in the Public Interest, 19(2), 59-92.

Grant, A. M., \& Schwartz, B. (2011). Too much of a good thing: The challenge and opportunity of the inverted $\mathrm{u}$. Perspectives on Psychological Science, 6(1), 61-76.

Grim, P., Singer, D. J., Bramson, A., Holman, B., McGeehan, S., \& Berger, W. J. (2019). Diversity, ability, and expertise in epistemic communities. Philosophy of Science, 86(1), 98-123.

Guest, O., \& Martin, A. E. (2021). How computational modeling can force theory building in psychological science. Perspectives on Psychological Science. doi: https://doi.org/10.31234/osf.io/rybh9

Gutiérrez, K. D., \& Rogoff, B. (2003). Cultural ways of learning: Individual traits or repertoires of practice. Educational Researcher, 32(5), 19-25.

Hahn, U., von Sydow, M., \& Merdes, C. (2019). How communication can make voters choose less well. Topics in Cognitive Science, 11(1), 194-206.

Hanel, P. H., Maio, G. R., Soares, A. K., Vione, K. C., de Holanda Coelho, G. L., Gouveia, V. V., ... Manstead, A. S. (2018). Cross-cultural differences and similarities in human value instantiation. Frontiers in Psychology, 9, 849.

Henrich, J., \& Gil-White, F. J. (2001). The evolution of prestige: Freely conferred deference as a mechanism for enhancing the benefits of cultural transmission. Evolution and Human Behavior, 22(3), 165-196.

Hoever, I. J., Van Knippenberg, D., Van Ginkel, W. P., \& Barkema, H. G. (2012). Fostering team creativity: perspective taking as key to unlocking diversity's po- tential. Journal of Applied Psychology, 97(5), 982.

Hofstra, B., Kulkarni, V. V., Galvez, S. M.-N., He, B., Jurafsky, D., \& McFarland, D. A. (2020). The diversityinnovation paradox in science. Proceedings of the $\mathrm{Na}$ tional Academy of Sciences, 117(17), 9284-9291.

Homan, A. C., Van Knippenberg, D., Van Kleef, G. A., \& De Dreu, C. K. (2007). Bridging faultlines by valuing diversity: diversity beliefs, information elaboration, and performance in diverse work groups. Journal of Applied Psychology, 92(5), 1189.

Hong, L., \& Page, S. E. (2001). Problem solving by heterogeneous agents. Journal of Economic Theory, 97(1), 123-163.

Hong, L., \& Page, S. E. (2004). Groups of diverse problem solvers can outperform groups of high-ability problem solvers. Proceedings of the National Academy of Sciences, 101(46), 16385-16389.

Hoogendoorn, S., Parker, S. C., \& Van Praag, M. (2017). Smart or diverse start-up teams? evidence from a field experiment. Organization Science, 28(6), 1010-1028.

Hoogendoorn, S., \& Van Praag, M. (2012). Ethnic diversity and team performance: A field experiment (Tech. Rep.). Tinbergen Institute Discussion Paper 12-068/3.

Horwitz, S. K., \& Horwitz, I. B. (2007). The effects of team diversity on team outcomes: A meta-analytic review of team demography. Journal of Management, 33(6), 987-1015.

Hunt, R. G., Krzystofiak, F. J., Meindl, J. R., \& Yousry, A. M. (1989). Cognitive style and decision making. Organizational Behavior and Human Decision Processes, 44(3), 436-453.

Intemann, K. (2009). Why diversity matters: Understanding and applying the diversity component of the national science foundation's broader impacts criterion. Social Epistemology, 23(3-4), 249-266.

Joshi, A., \& Roh, H. (2009). The role of context in work team diversity research: A meta-analytic review. Academy of Management Journal, 52(3), 599-627.

Kitcher, P. (1990). The division of cognitive labor. The Journal of Philosophy, 87(1), 5-22.

Kozhevnikov, M., Evans, C., \& Kosslyn, S. M. (2014). Cognitive style as environmentally sensitive individual differences in cognition: A modern synthesis and applications in education, business, and management. Psychological Science in the Public Interest, 15(1), 3-33.

Krzeminska, A., Austin, R. D., Bruyère, S. M., \& Hedley, D. (2019). The advantages and challenges of neurodiversity employment in organizations. Journal of Management $\mathcal{F}$ Organization, 25(4), 453-463.

Kuhn, T. S. (1977). Objectivity, value judgment, and theory choice. In T. S. Kuhn (Ed.), The essential tension: Select studies in scientific tradition and change (pp. 74-86). Chicago, IL: University of Chicago Press. 
Kwisthout, J. (2012). Relevancy in problem solving: A computational framework. The Journal of Problem Solving, 5(1), 18-33.

Laland, K. N. (2004). Social learning strategies. Animal Learning $\mathcal{F}$ Behavior, 32(1), 4-14.

Lazer, D., \& Friedman, A. (2007). The network structure of exploration and exploitation. Administrative Science Quarterly, 52(4), 667-694.

Leung, A. K.-y., \& Chiu, C.-y. (2010). Multicultural experience, idea receptiveness, and creativity. Journal of Cross-Cultural Psychology, 41(5-6), 723-741.

Levine, S. S., Apfelbaum, E. P., Bernard, M., Bartelt, V. L., Zajac, E. J., \& Stark, D. (2014). Ethnic diversity deflates price bubbles. Proceedings of the National Academy of Sciences, 111(52), 18524-18529.

LiCalzi, M., \& Surucu, O. (2012). The power of diversity over large solution spaces. Management Science, 58(7), 1408-1421.

Longino, H. E. (1995). Gender, politics, and the theoretical virtues. Synthese, 104(3), 383-397.

Longino, H. E. (2002). The fate of knowledge. Princeton University Press.

Lorenz, J., Rauhut, H., Schweitzer, F., \& Helbing, D. (2011). How social influence can undermine the wisdom of crowd effect. Proceedings of the National Academy of Sciences, 108(22), 9020-9025.

Lukaszewski, A. W., Gurven, M., von Rueden, C. R., \& Schmitt, D. P. (2017). What explains personality covariation? A test of the socioecological complexity hypothesis. Social Psychological and Personality Science, 8(8), 943-952.

Maddux, W. W., Adam, H., \& Galinsky, A. D. (2010). When in Rome... learn why the Romans do what they do: How multicultural learning experiences facilitate creativity. Personality and Social Psychology Bulletin, 36(6), 731-741.

Mann, R. P., \& Helbing, D. (2017). Optimal incentives for collective intelligence. Proceedings of the National Academy of Sciences, 114(20), 5077-5082.

Mannix, E., \& Neale, M. A. (2005). What differences make a difference? the promise and reality of diverse teams in organizations. Psychological Science in the Public Interest, 6(2), 31-55.

McLeod, P. L., Lobel, S. A., \& Cox, T. H., Jr. (1996). Ethnic diversity and creativity in small groups. Small Group Research, 27(2), 248-264.

Medin, D. L. (2017). Psychological science as a complex system: Report card. Perspectives on Psychological Science, 12(4), 669-674.

Mello, A. L., \& Rentsch, J. R. (2015). Cognitive diversity in teams: A multidisciplinary review. Small Group Research, 46(6), 623-658.

Mesoudi, A., Chang, L., Dall, S. R., \& Thornton, A. (2016).
The evolution of individual and cultural variation in social learning. Trends in Ecology $\mathcal{G}$ Evolution, 31(3), 215-225.

Mill, J. S. (1989). On liberty and other writings (S. Collini, Ed.). Cambridge University Press.

Molleman, L., Kurvers, R., \& van den Bos, W. (2019). Unleashing the BEAST: A brief measure of human social information use. Evolution and Human Behavior, 40(5), 492-499.

Monechi, B., Pullano, G., \& Loreto, V. (2019). Efficient team structures in an open-ended cooperative creativity experiment. Proceedings of the National Academy of Sciences, 116(44), 22088-22093.

Murrar, S., Campbell, M. R., \& Brauer, M. (2020). Exposure to peers' pro-diversity attitudes increases inclusion and reduces the achievement gap. Nature Human Behaviour, 1-9.

Murray, D., Siler, K., Larivière, V., Chan, W. M., Collings, A. M., Raymond, J., \& Sugimoto, C. R. (2019). Author-reviewer homophily in peer review. BioRxiv, 400515. doi: https://doi.org/10.1101/400515

Muthukrishna, M., \& Henrich, J. (2016). Innovation in the collective brain. Phil. Trans. R. Soc. B, 371(1690), 20150192.

Navajas, J., Niella, T., Garbulsky, G., Bahrami, B., \& Sigman, M. (2018). Aggregated knowledge from a small number of debates outperforms the wisdom of large crowds. Nature Human Behaviour, 2(2), 126.

Nemeth, C. J. (1995). Dissent as driving cognition, attitudes, and judgments. Social Cognition, 13(3), 273-291.

Nemeth, C. J., \& Wachtler, J. (1983). Creative problem solving as a result of majority vs minority influence. European Journal of Social Psychology, 13(1), 45-55.

Nielsen, M. W., Alegria, S., Börjeson, L., Etzkowitz, H., Falk-Krzesinski, H. J., Joshi, A., ... Schiebinger, L. (2017). Opinion: Gender diversity leads to better science. Proceedings of the National Academy of Sciences, 114(8), 1740-1742.

Nielsen, M. W., Bloch, C. W., \& Schiebinger, L. (2018). Making gender diversity work for scientific discovery and innovation. Nature Human Behaviour, 2(10), $726-734$.

Page, S. E. (2014). Where diversity comes from and why it matters? European Journal of Social Psychology, 44(4), 267-279.

Parrotta, P., Pozzoli, D., \& Pytlikova, M. (2014). The nexus between labor diversity and firm's innovation. Journal of Population Economics, 27(2), 303-364.

Paulus, P. B., \& Brown, V. R. (2007). Toward more creative and innovative group idea generation: A cognitivesocial-motivational perspective of brainstorming. Social and Personality Psychology Compass, 1(1), 248265. 
Paulus, P. B., van der Zee, K. I., \& Kenworthy, J. (2016). Cultural diversity and team creativity. In V. P. Glăveanu (Ed.), The Palgrave handbook of creativity and culture research (pp. 57-76). Springer.

Paulus, P. B., van der Zee, K. I., \& Kenworthy, J. (2019). Diversity and group creativity. The Oxford Handbook of Group Creativity and Innovation, 33-49.

Pescetelli, N., Rutherford, A., \& Rahwan, I. (2020). Diversity promotes collective intelligence in large groups but harms small ones. PsyArXiv, January 2. doi: 10.31234/osf.io/b8q2c

Phillips, K. W., Liljenquist, K. A., \& Neale, M. A. (2009). Is the pain worth the gain? The advantages and liabilities of agreeing with socially distinct newcomers. Personality and Social Psychology Bulletin, 35(3), 336-350.

Phillips, K. W., \& Loyd, D. L. (2006). When surface and deep-level diversity collide: The effects on dissenting group members. Organizational Behavior and Human Decision Processes, 99(2), 143-160.

Phillips, K. W., Northcraft, G. B., \& Neale, M. A. (2006). Surface-level diversity and decision-making in groups: When does deep-level similarity help? Group Processes $\mathcal{E}$ Intergroup Relations, 9(4), 467-482.

Polzer, J. T., Milton, L. P., \& Swarm Jr, W. B. (2002). Capitalizing on diversity: Interpersonal congruence in small work groups. Administrative Science Quarterly, 47(2), 296-324.

Pöyhönen, S. (2017). Value of cognitive diversity in science. Synthese, 194(11), 4519-4540.

Ragins, B. R., Lyness, K. S., Williams, L. J., \& Winkel, D. (2014). Life spillovers: The spillover of fear of home foreclosure to the workplace. Personnel Psychology, 67(4), 763-800.

Reichenbach, H. (1938). Experience and prediction. Chicago, IL: University of Chicago Press.

Roberson, Q., Ryan, A. M., \& Ragins, B. R. (2017). The evolution and future of diversity at work. Journal of Applied Psychology, 102(3), 483.

Roebuck, H., \& Lupyan, G. (2020). The internal representations questionnaire: Measuring modes of thinking. Behavior Research Methods, 1-18.

Salazar, M. R., Feitosa, J., \& Salas, E. (2017). Diversity and team creativity: Exploring underlying mechanisms. Group Dynamics: Theory, Research, and Practice, 21(4), 187.

Salganik, M. J., Dodds, P. S., \& Watts, D. J. (2006). Experimental study of inequality and unpredictability in an artificial cultural market. Science, 311(5762), 854856.

Sasaki, T., Granovskiy, B., Mann, R. P., Sumpter, D. J., \& Pratt, S. C. (2013). Ant colonies outperform individuals when a sensory discrimination task is difficult but not when it is easy. Proceedings of the National
Academy of Sciences, 110(34), 13769-13773.

Schruijer, I., \& Mostert, S. G. (1997). Creativity and sex composition: An experimental illustration. European Journal of Work and Organizational Psychology, 6(2), 175-182.

Shirado, H., \& Christakis, N. A. (2017). Locally noisy autonomous agents improve global human coordination in network experiments. Nature, 545(7654), 370.

Smaldino, P. E., Lukaszewski, A., von Rueden, C., \& Gurven, M. (2019). Niche diversity can explain crosscultural differences in personality structure. Nature Human Behaviour, 3(12), 1276-1283.

Sommers, S. R. (2006). On racial diversity and group decision making: identifying multiple effects of racial composition on jury deliberations. Journal of Personality and Social Psychology, 90(4), 597.

Sperber, D., \& Wilson, D. (1995). Relevance: Communication and cognition (2nd ed.). Malden, MA: Blackwell Publishing.

Stahl, G. K., Maznevski, M. L., Voigt, A., \& Jonsen, K. (2010). Unraveling the effects of cultural diversity in teams: A meta-analysis of research on multicultural work groups. Journal of International Business Studies, 41(4), 690-709.

Stasser, G., \& Titus, W. (1985). Pooling of unshared information in group decision making: Biased information sampling during discussion. Journal of Personality and Social Psychology, 48(6), 1467.

Sternberg, R. J. (1995). Expertise in complex problem solving: A comparison of alternative conceptions. In P. A. Frensch \& J. Funke (Eds.), Complex problem solving: The European perspective (pp. 295-321). Lawrence Erlbaum Associates, Inc.

Sulik, J. (2018). Cognitive mechanisms for inferring the meaning of novel signals during symbolisation. PloS One, 13(1), e0189540.

Sulik, J., Bahrami, B., \& Deroy, O. (2021). Tolerance for failure unleashes the benefits of cognitive diversity in collective problem solving. PsyArXiv, https://psyarxiv.com/3es76.

Sulik, J., \& Lupyan, G. (2018). Perspective taking in a novel signaling task: effects of world knowledge and contextual constraint. Journal of Experimental Psychology: General, 147(11), 1619-1640.

Surowiecki, J. (2004). The wisdom of crowds: Why the many are smarter than the few and how collective wisdom shapes business, economies, societies and nations. New York: Knopf Doubleday Publishing Group.

Tadmor, C. T., Tetlock, P. E., \& Peng, K. (2009). Acculturation strategies and integrative complexity: The cognitive implications of biculturalism. Journal of CrossCultural Psychology, 40(1), 105-139.

Taras, V., Kirkman, B. L., \& Steel, P. (2010). Examining 
the impact of culture's consequences: A three-decade, multilevel, meta-analytic review of Hofstede's cultural value dimensions. Journal of Applied Psychology, 95(3), 405.

Thoma, J. (2015). The epistemic division of labor revisited. Philosophy of Science, 82(3), 454-472.

Todd, A. R., Hanko, K., Galinsky, A. D., \& Mussweiler, T. (2011). When focusing on differences leads to similar perspectives. Psychological Science, 22(1), 134-141.

Toyokawa, W., Whalen, A., \& Laland, K. (2019). Social learning strategies regulate the wisdom and madness of interactive crowds. Nature Human Behaviour, 3(2), 183-192.

Tylén, K., Fusaroli, R., Smith, P., \& Arnoldi, J. (2020). The social route to abstraction: interaction and diversity enhance rule-formation and transfer in a categorization task. PsyArXiv, August 13. doi: 10.31234/osf.io/ qs 253

Van Dijk, H., Van Engen, M. L., \& Van Knippenberg, D. (2012). Defying conventional wisdom: A metaanalytical examination of the differences between demographic and job-related diversity relationships with performance. Organizational Behavior and Human Decision Processes, 119(1), 38-53.

Van Knippenberg, D., De Dreu, C. K., \& Homan, A. C. (2004). Work group diversity and group performance: An integrative model and research agenda. Journal of Applied Psychology, 89(6), 1008.

Van Knippenberg, D., \& Schippers, M. C. (2007). Work group diversity. Annual Review of Psychology, 58, $515-541$.

Van Rooij, I. (2008). The tractable cognition thesis. Cognitive Science, 32(6), 939-984.

Viator, R. E., Harp, N. L., Rinaldo, S. B., \& Marquardt, B. B. (2019). The mediating effect of reflective-analytic cognitive style on rational thought. Thinking $\mathcal{F}$ Reasoning, $1-33$.

Waldron, J. (1995). The wisdom of the multitude: some reflections on book 3, chapter 11 of Aristotle's politics. Political Theory, 23(4), 563-584.

Wang, J., Cheng, G. H.-L., Chen, T., \& Leung, K. (2019). Team creativity/innovation in culturally diverse teams: A meta-analysis. Journal of Organizational Behavior, 40(6), 693-708.

Watson, W. E., Kumar, K., \& Michaelsen, L. K. (1993). Cultural diversity's impact on interaction process and performance: Comparing homogeneous and diverse task groups. Academy of management journal, 36(3), 590602.

Weatherall, J. O., \& O’Connor, C. (2020). Conformity in scientific networks. Synthese, 1-22.

Weisberg, M., \& Muldoon, R. (2009). Epistemic landscapes and the division of cognitive labor. Philosophy of Sci- ence, 76(2), 225-252.

West, D., \& Dellana, S. (2009). Diversity of ability and cognitive style for group decision processes. Information Sciences, 179(5), 542-558.

Williams, K. Y., \& O’Reilly, C. A. (1998). Demography and diversity in organizations: A review of 40 years of research. Research in Organizational Behavior, 20, 77-140.

Woolley, A. W., Chabris, C. F., Pentland, A., Hashmi, N., \& Malone, T. W. (2010). Evidence for a collective intelligence factor in the performance of human groups. Science, 330(6004), 686-688.

Yahosseini, K. S., \& Moussaïd, M. (2019). The social dynamics of collective problem-solving. bioRxiv. doi: 10.1101/771014

Yahosseini, K. S., Reijula, S., Molleman, L., \& Moussaïd, M. (2018). Social information can undermine individual performance in exploration-exploitation tasks. In C. Kalish, M. Rau, J. Zhu, \& T. Rogers (Eds.), CogSci 2018 (pp. 2473-2478).

Zollman, K. J. (2010). The epistemic benefit of transient diversity. Erkenntnis, 72(1), 17-35. 